\title{
Pengaruh Pelayanan Digital dan Pelayanan Konvensional terhadap Kepuasan Nasabah Bank Sumsel Babel Cabang Prabumulih
}

\author{
Andi Mawardi ${ }^{1)}$, Hasmawaty, A.R. ${ }^{2)}$ \\ 1), 2), Universitas Bina Darma, Palembang \\ Email: andimawaradi.mmubd@gmail.com ${ }^{1)}$, hasmawaty@binadarma.co.id ${ }^{2}$
}

\begin{abstract}
This study aims to analyze the magnitude of the influence of digital services and conventional services on customer satisfaction at Bank Sumsel Babel Prabumulih Branch. Primary data obtained from the results of customer questionnaire answers as many as 140 customers. The collection of population samples is carried out without regard to the existing stratum in the population (sample random sampling). Data is obtained from customers who make transactions from April 2021 - June 2021. Data analysis uses the SPSS program. From the results of the analysis, it is found that digital services have no significant effect on customer satisfaction. However, conventional services have a significant effect on customer satisfaction.
\end{abstract}

Keywords: digital services, counter services, customer satisfaction

\begin{abstract}
Abstrak
Penelitian ini bertujuan untuk menganalisis besarnya Pengaruh pelayanaan digital dan pelayanan konvensioal terhadap kepuasan nasabah di Bank Sumsel Babel Cabang Prabumulih. Data primer diperoleh dari hasil jawaban kuesioner nasabah sebanyak 140 nasabah. Pengumpulan sampel populasi dilakukan secara tanpa memperhatikan strarta yang ada dalam populasi (sample random sampling). Data diperoleh dari nasabah yang melakukan transaksi dari bulan bulan April 2021 - Juni 2021. Analisis data menggunakan program SPSS. Dari hasil analisis diperoleh bahwa pelayanan digital tidak berpengaruh signifikan terhadap kepuasan nasabah. Akan tetapi pelayanan konvensional berpengaruh signifikan terhadap kepuasan nasabah.
\end{abstract}

Kata kunci: pelayanan digital, pelayanan konvesional, kepuasan nasabah

\section{Pendahuluan}

\subsection{Latar Belakang}

Pandemi Covid-19 membawa dampak pada berbagai sektor bisnis di seluruh dunia, termasuk industri jasa keuangan. Pandemi Covid-19 mengubah perilaku konsumen mulai dari beradaptasi, mengadopsi dan berkolaborasi dengan ekosistem digital. Perubahan juga terjadi pada perbankan di Indonesia, sistem pelayanan dan Operasional berubah dari pelayanan secara konvensional ke digital banking.

Dalam kondisi normal, nasabah melakukan transaksi perbankan langsung di kantor-kantor kas dan cabang serta bertatap muka langsung dengan staff pelayanan perbankan. Tetapi sekarang transaksi nasabah dilakukan secara digital banking yaitu sms banking, internet banking dan mobile banking. Pandemi Covid-19 mendorong dan memperkuat pergeseran layanan nasabah dari konvensional ke layanan digital.

Nasabah menilai kualitas layanan konvensional selama proses layanan tatap muka berlangsung. Kontak/tatap muka secara langsung antara penyedia layanan dan pelanggan adalah kunci dalam evaluasi kinerja layanan perbankan. Pengalaman layanan dan kepuasan konsumen ditentukan 
oleh interaksi dengan organisasi, proses dan para karyawan.

Perkembangan teknologi menciptakan konsep layanan dan lingkungan layanan baru pada perbankan. Teknologi telah mengubah sifat pembelian dan pelayanan pada nasabah perbankan. Salah satu perubahan mendasar dalam industri perbankan adalah pergerakan konsumen dari konvensional ke e-banking seperti internet banking, sms banking dan phone banking di perbankan swasta. Teknologi memiliki pengaruh signifikan terhadap bisnis perbankan, khususnya dalam memberikan layanan berkualitas dan kepuasan kepada pelanggan (Maitlo, 2015).

PT Bank Pembangunan Daerah Sumatera Selatan dan Bangka Belitung didirikan pada tanggal 6 November 1957 sebagai salah satu perbankan yang ada di Wilayah Sumatera Selatan. Bank Sumsel Babel memiliki produk perbankan yaitu Deposito, Tabungan, Giro, Kredit, Kartu Kredit dan BSB Cash. Bank Sumsel Babel memiliki pelayanan digital yaitu SMS Banking, Phone Banking dan Mobile Banking. Tabel 1.1 menunjukan data nasabah pengguna layanan digital di Bank Sumsel Babel dari tahun 2018 sampai dengan akhir bulan Desember 2020.

Tabel 1. Data Nasabah Pengguna Layanan Digital per Desember 2020 Bank Sumsel Babel Kantor Cabang Prabumulih

\begin{tabular}{clccc}
\hline Tahun & \multicolumn{1}{c}{$\begin{array}{c}\text { Nama } \\
\text { Produk }\end{array}$} & $\begin{array}{c}\text { Total } \\
\text { Nasabah } \\
\text { Funding }\end{array}$ & $\begin{array}{c}\text { Total Nasabah } \\
\text { Pengguna } \\
\text { Produk }\end{array}$ & $\begin{array}{c}\text { Percentasi } \\
\text { (\%) }\end{array}$ \\
\hline \multirow{2}{*}{2018} & SMS Banking & 34.085 & 9.448 & 27 \\
& Internet & & 30 & 0.08 \\
& Banking & & 230 & 0.67 \\
& Mobile & & & \\
& Banking & & 12.432 & 33.2 \\
& SMS Banking & 37.410 & 97 & 0.25 \\
& Internet & & 430 & 1.14 \\
& Banking & & & \\
& Mobile & & 18.164 & 44.36 \\
& Banking & & 467 & 1.14 \\
& SMS Banking & 40.943 & 1.553 & 3.79 \\
& Internet & & & \\
\hline
\end{tabular}

Sumber: Data sekunder Bank Sumsel Babel Cabang Prabumulih, 2021

Tabel 1.1 menunjukan data pengguna layanan digital di Bank Sumsel Babel khususnya Cabang Prabumulih dari tahun 2018 sampai dengan 2020. Dapat dilihat pada Tabel bahwa masih sedikit jumlah nasabah pengguna layanan digital pada Bank Sumsel Babel Cabang Prabumulih. Sebagai dampak dari pandemic Covid-19 pada akhir Desember 2020 jumlah nasabah pengguna layanan digital meningkat sebanyak $44.36 \%$ pengguna SMS Banking, 1.14\% pengguna Internet Banking dan 3.79\% pengguna Mobile Banking. Tetapi jumlah tersebut masih di bawah 50\% 
dari total nasabah funding Bank Sumsel Babeel Cabang Prabumulih. Hal ini menjadi suatu tantangan untuk Bank Sumsel Babel meningkatkan jumlah nasabah pengguna layanan digital.

\subsection{Rumusan Masalah}

Berdasarkan uraian latar belakang diatas penelitian ini merumusakan masalah mengenai Pengaruh pelayanan digital dan pelayanan konvesional terhadap kepuasan nasabah di Bank Sumsel Babel Cabang Prabumulih.

\subsection{Tujuan Penelitian}

Tujuan dari penelitian ini adalah untuk menganalisis Pengaruh pelayanan digital dan pelayanan konvesional terhadap kepuasan nasabah di Bank Sumsel Babel Cabang Prabumulih.

\section{Landasan Teori}

\subsection{Pelayanan Digital}

Layanan Digital merupakan bagian integral dari mCommerce menjadi sangat populer di kalangan pengguna ponsel sejak tahun 2007. Layanan Digital menciptakan komunikasi baru yang nyaman dan saluran transaksi keuangan cepat untuk pengguna ponsel. Pelayanan dapat diakses di mana saja, kapan saja, untuk memeriksa akun informasi, saldo tersedia, informasi kartu kredit / debit, status cek, pengingat pembayaran, lokasi ATM dan cabang bank, mengakses laporan pinjaman dan ekuitas, manajemen kebijakan asuransi, atau menempatkan pesanan untuk buku cek, melalui ponsel adalah beberapa layanan yang ditawarkan dalam mobile banking (Sarma, 2011).

Mobile banking adalah sebuah layanan yang memungkinkan nasabah melakukan transaksi perbankan melalui ponsel atau smartphone. Nasabah dapat menikmati layanan mobile banking melalui menu yang sudah tersedia pada aplikasi mobile banking yang telah diunduh dan install oleh nasabah dengan mendaftarkan diri terlebih dahulu ke bank untuk mendapatkan user ID dan password untuk digunakan saat nasabah akan melakukan log in pada aplikasi mobile banking.

Penelitian ini mendekati penelitian (Sarma, 2011) yang berdasarkan ESERVQUAL Parasuraman et al (2005) dan telah dimodifikasi yang dapat lima dimensi E-S-QUAL yang digunakan pada penelitian ini, yaitu:

1. Keandalan dan Responsivitas (Reliability and Responsiveness)

2. Jaminan dan Keamanan (Assurance and Security)

3. Kenyamanan (Convenience)

4. Efesiensi (Efficiency)

5. Mudah untuk digunakan (Easy to Operate)

\subsection{Pelayanan Konvesional}

Kualitas pelayanan konvensional (counter) adalah salah satu dimensi penting dalam memberikan kepuasan kepada pelanggan dan juga mempertahankan mereka dalam bisnis perbankan. Kualitas pelayanan counter memenuhi kebutuhan pelanggan pada waktu yang tepat dan dengan cara yang benar. Strategi yang disarankan oleh para bankir dalam rangka kinerja mereka adalah fasilitas fisik, penggunaan teknologi informasi, kepedulian terhadap pelanggan dan menunjuk lebih banyak personel layanan (staf) (Misrha, 2010).

Penelitian ini mendekati penelitian Ahmed (2017) menggunakan tiga dimensi kualitas layanan 
untuk operasional perbankan. Penelitian ini mengukur kualitas layanan bagi bank untuk memperoleh kepuasan nasabah. Kuesioner adalah diadaptasi dan dimodifikasi sesuai dengan dimensi SERVQUAL. SERVQUAL yang dikembangkan oleh Parasuraman, Zeithaml, dan Berry atau disingkat PZB $(1985,1988,1991)$ merupakan instrumen yang paling luas digunakan untuk mengukur kualitas jasa.

Lima dimensi kualitas layanan perbankan pada penelitian berdasarkan SERVQUAL yang dikembangkan oleh Parasuraman sebagai berikut:

\section{Reliability \\ 2. Assurance \\ 3. Tangibles \\ 4. Emphaty \\ 5. Responsiveness \\ 2.3 Kepuasan Nasabah}

Kepuasan adalah perasaan seseorang dalam membandingkan harapan dengan hasil yang dirasakan. Menurut Kasmir (2008), pengukuran tingkat kepuasan pelanggan ada 4 cara, yaitu sistem keluhan dan usulan, survei kepuasan konsumen, konsumen samaran (mystery guest), dan analisis mantan pelanggan. Dalam pengukuran tingkat kepuasan pelanggan, pelaku usaha harus mengukur langsung dengan berbagai pertanyaan mengenai pelayanan produk dan jasa yang diberikan, atau memberikan sarana agar pelanggan bisa menuliskan kritik atau saran serta merangking seberapa besar tingkat kepuasan yang pelanggan rasakan.

\subsection{Hubungan antar Variabel}

\subsubsection{Hubungan Pelayanan Konvensional dengan Kepuasan Nasabah}

Abdullah (2014), menemukan bahwa kualitas pelayanan counter berpengaruh signifikan terhadap kepuasan nasabah. Kualitas pelayanan counter yaitu fasilitas perbankan dan kesopanan karyawan memiliki hubungan yang kuat dengan kepuasan pelanggan secara keseluruhan (Anderson dan Sullivan, 1993). Pada dasarnya, fasilitas perbankan dan persepsi positif saling terkait satu sama lain dan ada hubungan sebab akibat yang kuat untuk kepuasan pelanggan.

H1: Pelayanan konvensional berpengaruh terhadap kepuasan nasabah

\subsubsection{Hubungan Pelayanan Digital dan Kepuasan Nasabah}

Ahmed (2017), menemukan bahwa penggunaan pelayanan digital meningkatkan tingkat kepuasan pelanggan secara signifikan di sektor perbankan Pakistan. Pelayanan digital memainkan peran penting dalam memberikan layanan perbankan yang efektif dan efisien yang meningkatkan kepuasan pelanggan. Karena sistem yang terintegrasi secara teknologi, bank sekarang dapat tampil lebih kompetitif dan efisien di pasar keuangan.

H2: Pelayanan digital berpengaruh terhadap kepuasan nasabah

\subsection{Kerangka Pikir}

Berdasarkan fenomena dan hasil penelitian terdahulu maka kerangka pikir pada penelitian ini adalah sebagai berikut: 


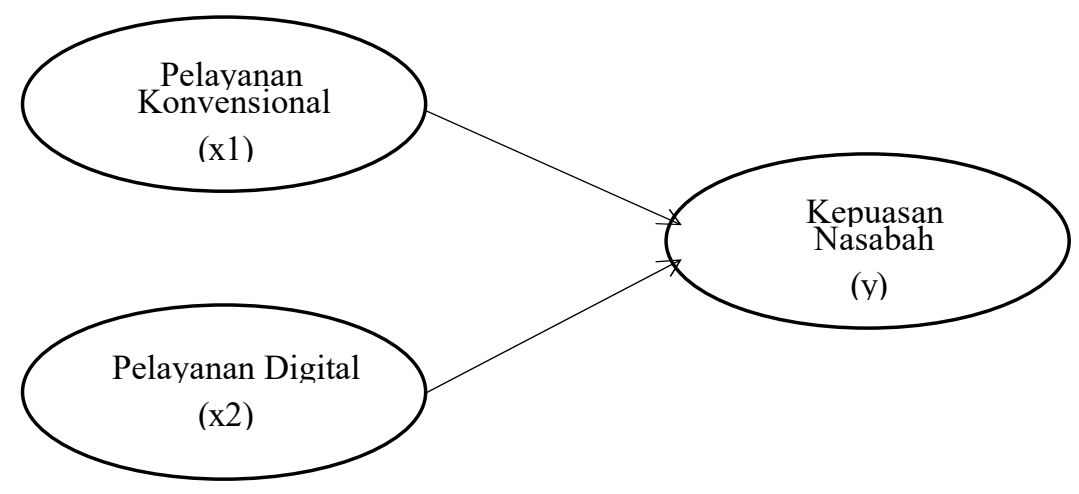

Gambar.1 Kerangka Konseptual Penelitian

\section{Metodologi Penelitian}

\subsection{Populasi dan Sampel}

Populasi pada penelitian ini adalah keseluruhan total nasabah Bank Sumsel Babel Cabang Prabumulih. Teknik pengambilan sample menggunakan teknik probability sampling. Pengambilan sampel populasi dilakukan secara acak tanpa memperhatikan strata yang ada dalam populasi (sample random sampling). Pengambilan sample dilakukan selama 3 bulan terakhir dimulai dari 25 April 2021 sampai dengan 25 juni 2021 yang berjumlah 215 orang. Berdasarkan Rumus Slovin hasil perhitungan diatas maka karyawan yang dijadikan sampel (n) pada penelitian ini adalah sebanyak 140 orang.

\subsection{Teknik Pengumpulan Data}

Teknik pengumpulan data pada penelitian ini menggunakan kuesioner, dimana teknik ini memiliki keunggulan tersendiri dibanding wawancara, yakni secara kuantitatif, peneliti dapat memperoleh banyak data yang tersebar dalam suatu wilayah (Keraf, 2004). Metode pengambilan sampel ini dilakukan dengan memilih nasabah yang sedang melakukan transaksi di Bank Sumsel Babel Cabang Prabumulih.

\section{Analisis Dan Pembahasan}

Penelitian ini menggunakan analisis deskriptif dan kuantitatif. Deskriptif Analisis berfungsi untuk menggambarkan distribusi frekuensi jawaban responden terhadap variabel. Sedangkan analisis kuantitatif dari paket statistik SPSS.

\subsection{Analisis Deskritif}

Respondent merupakan nasabah Bank Sumsel Babel Cabang Prabumulih, periode transaksi bulan April 2021 - Juni 2021. Adapun informasi karakteristik data respondent ditunjukan pada Tabel 2, dibawah ini:

Tabel 2. Data Respondent

\begin{tabular}{clcc}
\hline No & Kategori & Jumlah $(\mathbf{N})$ & Persentase (\%) \\
\hline $\mathbf{1}$ & Jenis Kelamin & & \\
& Laki-laki & 91 & 45.5 \\
& Perempuan & 109 & 54.5
\end{tabular}




\section{$2 \quad$ Usia}

$\begin{array}{llc}17-25 \text { tahun } & 37 & 18.5 \\ 26-35 \text { tahun } & 44 & 22 \\ 36-45 \text { tahun } & 89 & 44.5 \\ >45 \text { tahun } & 30 & 15\end{array}$

\section{Pendidikan}

SMA

Diploma

S1

$\mathrm{S} 2 / \mathrm{S} 3$

\section{Pekerjaan}

PNS

BUMN/BUMD

Pegawai Swasta

Wiraswasta

Mahasiswa

\section{Sumber: data olahan, 2021}

Berdasarkan Tabel 2 diatas, karakteristik jenis kelamin, jumlah responden perempuan 54.5\% dan $45.5 \%$ responden laki-laki. Perbedaan persentase ini tidak telalu besar mengingat baik perempuan maupun laki-laki memiliki kebutuhan terhadap jasa perbankan dalam kehidupan sehari-hari.

Dilihat dari data kategori data usia responden, dalam penelitian ini mayoritas responden berusia antara 36-45 tahun dengan persentase sebesar 44.5\% yang dilanjutkan dengan responden yang berusia 26-35 tahun dengan persentase 22\%. Usia 17-25 tahun memiliki persentase sebesar $18.5 \%$ yang dilanjutkan dengan usia lebih dari 45 tahun dengan persentase $15 \%$.

Jika dilihat dari karakteristik berdasarkan pendidikan terakhir, mayoritas responden berpendidikan Sarjana (S1) dengan persentase 52.5\%. 18.5\% adalah responden yang memiliki pendidikan terakhir Diploma, dan sisanya sebesar $14.5 \%$ masing-masing adalah responden dengan jenjang pendidikan di tingkat SMA dan S2/S3.

Dari sisi jenis pekerjaan, dalam penelitian ini $115 \%$ responden memiliki pekerjaan sebagai PNS. Responden yang bekerja sebagai pegawai BUMN/BUMD adalah sebesar 18.5\%, responden yang bekerja sebagai Pegawai Swasta adalah sebesar 15\%, dan yang menjalani pekerjaan sebagai wiraswasta sebesar 7.5\%. Masih terdapat responden yang belum bekerja atau berstatus sebagai mahasiswa dengan persentase sebesar 3\%. Hal ini menunjukan bahwa mayoritas nasabah Bank Sumsel Babel Cabang Prabumulih adalah merupakan PNS.

\subsection{Uji Kualitas Data}

Data tida akan berguna jika tidak memiliki validitas (kesahihan) dan reliabilitas (kesahihan). Oleh karena itu uji validitas dan uji reliabititas diperlukan untuk mengukur kesahihan dan 
kehandalan data yang diperoleh.

\subsubsection{Uji Validitas}

Uji Validitas digunakan untuk mengukur ketepatan dan kecepatan suatu instrumen penelitian, dalam penentuan layak atau tidaknya suatu item yang digunakan biasanya dilakukan uji signifikan, artinya dianggap valid jika berkorelasi signifikan terhadap jumlah pertanyaan dalam kuisioner. Dianggap Valid apabila R-hitung lebih besar dari R-tabel $(0,165)$ atau nilai Sig 2tailed lebih kecil dari 0,05. Akan dilakukan uji validitas untuk setiap variabel yang akan disajikan dalam tabel dibawah.Pengujian dilakukan dengan bantuan aplikasi SPSS.

Tabel 3. Hasil Uji Validitas Pelayanan Digital (X1)

\begin{tabular}{llll}
\hline Pertanyaan & R hitung & Sig 2-tailed & Keterangan \\
\hline pertanyaan 1 & 0.189 & 0,025 & Valid \\
pertanyaan 2 & 0.251 & 0,003 & Valid \\
pertanyaan 3 & 0.752 & 0,000 & Valid \\
pertanyaan 4 & $-0,014$ & 0,869 & Tidak Valid \\
pertanyaan 5 & 0.540 & 0,000 & Valid \\
pertanyaan 6 & 0.752 & 0,000 & Valid \\
pertanyaan 7 & 0752 & 0,000 & Valid \\
pertanyaan 8 & 0.540 & 0,000 & Valid \\
pertanyaan 9 & 0.540 & 0,000 & Valid \\
pertanyaan 10 & 0.752 & 0,000 & Valid \\
pertanyaan 11 & 0.752 & 0,000 & Valid \\
Pertanyaan & $\mathrm{R}$ hitung & Sig 2-tailed & Keterangan \\
pertanyaan 12 & 0.540 & 0,000 & Valid \\
pertanyaan 13 & 0.165 & 0,050 & Valid \\
pertanyaan 14 & 0.165 & 0,050 & Valid \\
pertanyaan 15 & 0.752 & 0,000 & Valid \\
\hline
\end{tabular}

Sumber: Data Primer yang diolah, 2021

Berdasarkan table 4.6 di atas dapat disimpulkan bahwa Sebagian besar butir pertanyaan pada variable Pelayanan Digital (X1) dinyatakan valid, hal ini dibuktikan dengan nilai R hitung lebih besar dari R table, dan nilai Sig 2-tailed lebih kecil dari 0,05.

Tabel 4. Hasil Uji Validitas Pelayanan konvensional (X2)

\begin{tabular}{llcl}
\hline Pertanyaan & R hitung & Sig 2-tailed & Keterangan \\
\hline pertanyaan 1 & 0.259 & 0,002 & Valid \\
pertanyaan 2 & 0.678 & 0,000 & Valid \\
pertanyaan 3 & 0678 & 0,000 & Valid \\
\hline
\end{tabular}




\begin{tabular}{llcl}
\hline pertanyaan 4 & -0.070 & 0,411 & Tidak Valid \\
pertanyaan 5 & 0.544 & 0,000 & Valid \\
pertanyaan 6 & 0.544 & 0,000 & Valid \\
pertanyaan 7 & 0.279 & 0,001 & Valid \\
pertanyaan 8 & 0.112 & 0,189 & Tidak Valid \\
pertanyaan 9 & 0,550 & 0,000 & Valid \\
Pertanyaan & R hitung & Sig 2-tailed & Keterangan \\
\hline pertanyaan 10 & 0.581 & 0,000 & Valid \\
pertanyaan 11 & 0.581 & 0,000 & Valid \\
pertanyaan 12 & 0.678 & 0,000 & Valid \\
pertanyaan 13 & 0.000 & 0,000 & Valid \\
pertanyaan 14 & 0.463 & 0,000 & Valid \\
pertanyaan 15 & 0.451 & 0,000 & Valid \\
\hline
\end{tabular}

Sumber: Data Primer yang diolah, 2021

Berdasarkan table 4.7 di atas dapat disimpulkan bahwa ssebagian besar butir pertanyaan pada variable Pelayanan konvensional (X2) dinyatakan valid, hal ini dibuktikan dengan nilai $\mathrm{R}$ hitung lebih besar dari R table, dan nilai Sig 2-tailed lebih kecil dari 0,05.

Tabel 5 Hasil Uji Validitas Kepuasan Nasabah (Y)

\begin{tabular}{llll}
\hline Pertanyaan & R hitung & R tabel & Keterangan \\
\hline pertanyaan 1 & 0.314 & 0,000 & Valid \\
pertanyaan 2 & 0.000 & 0,000 & Valid \\
pertanyaan 3 & 0.956 & 0,000 & Valid \\
pertanyaan 4 & 0.936 & 0,000 & Valid \\
pertanyaan 5 & 0.949 & 0,000 & Valid \\
pertanyaan 6 & 0.956 & 0,000 & Valid \\
pertanyaan 7 & 0956 & 0,000 & Valid \\
\hline
\end{tabular}

Sumber: Data Primer yang diolah, 2021

Berdasarkan table 4.8 di atas dapat disimpulkan bahwa seluruh butir pertanyaan pada variable Kepuasan Nasabah (Y) dinyatakan valid, hal ini dibuktikan dengan nilai R hitung lebih besar dari R table, dan nilai Sig 2-tailed lebih kecil dari 0,05.

Berdasarkan hasil perhitungan dengan mengunakan aplikasi spss, diketahui bahwa setiap pertanyaan di variabel Pelayanan Digital, variabel Pelayanan konvensional, dan variabel Kepuasan Nasabah memiliki R-hitung lebih besar R-tabel sehingga dapat disimpulkan bahwa seluruh butir pertanyaan dinyatakan Valid dan dapat dilakukan pengujian selanjutnya. 


\subsection{Uji Realibitas}

Uji Reliabilitas adalah pengujian dengan tujuan menguji tingkat stabilitas atau konsistensi suatu alat ukur. Pengujian reliabilitas dalam penelitian ini menggunakan Cronchbach's Alpha. Menurut Wiratna Sujerwani (2014), indriantoro dan bambang (2010), kuisioner dinyatakan reliabel apabila memiliki Cronchbach's Alpha lebih besar dari 0,70. Pengujian dilakukan dengan bantuan aplikasi SPSS.

Hasil uji reabilitas pada masing-masing Variabel Pelayanan Digital (X1), Pelayanan konvensional (X2), dan Kepuasan Nasabah (Y) disajikan pada tabel 6.

Tabel 6. Hasi Uji Reliabilitas

\begin{tabular}{|c|c|c|}
\hline Variabel Penelitian & $\begin{array}{l}\text { Nilai Cronchbach's } \\
\text { Alpha }\end{array}$ & Keterangan \\
\hline Pelayanan Digital (X1) & 0.732 & Reliabel \\
\hline Pelayanan konvensional (X2) & 0.714 & Reliabel \\
\hline Kepuasan Nasabah (Y) & 0.871 & Reliabel \\
\hline
\end{tabular}

Sumber: Data Primer yang diolah, 2021

Berdasarkan hasil uji reliabilitas diatas bahwa Nilai Cronchbach's Alpha variabel Pelayanan Digital (x1), variabel Pelayanan konvensional (x2), dan variabel Kepuasan Nasabah (y) lebih besar dari 0,70, sehingga seluruh butir pertanyaan terkait variabel Pelayanan Digital (x1), variabel Pelayanan konvensional (x2), dan variabel Kepuasan Nasabah (y) dinyatakan reliabel.

\subsection{Uji Hipotesis}

Pengujian hipotesis dalam penelitian bertujuan untuk membuktikan pengaruh variabel independen yang meliputi Pelayanan Digital, dan Pelayanan konvensional terhadap Kepuasan Nasabah pada Bank Sumsel Babel Cabang Prabumulih. Analisis data yang digunakan dalam pengajuan hipotesis penelitian ini adalah regresi berganda. Berikut ini akan dibahas hasil analisis regresi berganda yang dilakukan dengan SPSS Versi 25. jika nilai Sig. $<0,05$ maka artinya variable independent $(\mathrm{X})$ secara parsial berpengaruh terhadap variable dependen $(\mathrm{Y})$.

Tabel 7. Hasi Perhitungan Regresi Linier Berganda

\section{Coefficients $^{\mathrm{a}}$}

$\begin{array}{ll}\text { Unstandardized } & \text { Standardized } \\ \text { Coefficients } & \text { Coefficients }\end{array}$

\begin{tabular}{lllllll} 
Model & B & Std. Error & Beta & t & Sig. \\
\hline 1 & (Constant) & 6.784 & 2.975 & & 2.280 & .024 \\
& $\begin{array}{l}\text { pelayanan digital } \\
\text { pelayanan }\end{array}$ & .255 & .047 & .488 & 5.432 & .000 \\
& konvensional & .099 & .062 & .143 & 1.596 & .113
\end{tabular}

a. Dependent Variable: kepuasan nasabah

Sumber: SPSS, 2021. 


$$
\begin{aligned}
& \mathrm{Y}=\mathrm{C}+\mathrm{b} 1 \mathrm{X} 1+\mathrm{b} 2 \mathrm{X} 2+\mathrm{e} \\
& \mathrm{Y}=6.784+0.255 \mathrm{X} 1+0.099 \mathrm{X} 2+\mathrm{e}
\end{aligned}
$$

Berdasarkan rangkuman hasil analisis regresi berganda diatas:

1. Uji Hipotesis 1

Berdasarkan tabel output SPSS diatas diketahui bahwa nilai (sig) Variabel Pelayanan Digital (X1) adalah 0.000. karena nilai (sig) $<0.05$ maka disimpulkan bahwa Hipotesis 1 ditolak, artinya tidak ada pengaruh yang signifikan antara Pelayanan Digital (X1) terhadap Kepuasan Nasabah (Y).

2. Uji Hipotesis 2

Berdasarkan tabel output SPSS diatas diketahui bahwa nilai (sig) Variabel Pelayanan konvensional (X2) adalah sebesar 0.113. karena nilai (sig) $>0.05$ maka disimpulkan bahwa Hipotesis 2 diterima, artinya ada pengaruh yang signifikan antara Pelayanan Digital (X2) terhadap Kepuasan Nasabah (Y).

\section{Kesimpulan Dan Sarana}

\subsection{Kesimpulan}

Berdasarkan hasil pengolahan pada bab sebelumnya diketahui bahwa nilai (sig) Variabel Pelayanan Digital (X1) adalah 0.000. karena nilai (sig) $<0.05$ maka disimpulkan bahwa Hipotesis 1 ditolak, artinya tidak ada pengaruh yang signifikan antara Pelayanan Digital (X1) terhadap Kepuasan Nasabah (Y).

Sedangkan untuk variabel Pelayanan konvensional (X2) adalah sebesar 0.113. karena nilai $(\mathrm{sig})>0.05$ maka disimpulkan bahwa Hipotesis 2 diterima, artinya ada pengaruh yang signifikan antara Pelayanan Digital (X2) terhadap Kepuasan Nasabah (Y).

Berdasarkan hasil pengolahan data diatas maka dapat diperoleh kesimpulan sebagai berikut :

1. Variabel pelayanan digital dengan dimensi Reability Service, Fullfilment, Security, Responsiveness, Easy to Use dirasakan tidak begitu berpengaruh terhadap kepuasan nasabah di Bank Sumsel Babel Cabang Prabumulih. Para nasabah pada penelitian ini belum terbiasa dengan pelayanan digital sebagai layanan perbankan yang efektif dan efisien untuk meningkatkan kepuasan pelanggan.

2. Hasil penelitian pelayanan konvensional menyimpulkan bahwa lima dimensi (Reliability, Assurance, Tangibles, Emphaty, Responsiveness) kualitas layanan (SERVQUAL) berpengaruh positif signifikan terhadap kepuasan nasabah. Hasil penelitian ini didukung oleh penelitian (Ahmed, 2017) menegaskan bahwa kualitas layanan bersama kelima dimensi membawa keandalan yang konsisten dan masing-masing secara signifikan dan positif terkait dengan dimensi kualitas layanan perbankan konvensional secara signifikan berpengaruh positif terhadap kepuasan nasabah.

3. Dimensi layanan konvensional sangat penting dan berharga di Bank Sumsel Babel Cabang Prabumulih. Fasilitas perbankan seperti fasilitas cabang ritel bank, pemeliharaan, jenis layanan, kecenderungan membantu pelanggan, kenyamanan dan fasilitas bangunan. Kesopanan, ketanggapan dan empati karyawan juga dianggap sebagai inti untuk hubungan nasabah dan kinerja dipandang sebagai komponen kunci yang signifikan untuk kesuksesan pelayanan konvensional Bank Sumsel Babel Cabang Prabumulih. Kepuasan nasabah 
tercipta karena adanya hubungan kuat antara fasilitas perbankan dan nasabah secara keseluruhan (Abdullah, 2014).

\subsection{Saran-Saran}

Berdasarkan kesimpulan diatas, saran yang dapat disampaikan adalah sebagai berikut :

1. Kepada Manajemen Bank Sumsel Babel harus menyadari pentingnya infrastruktur inovatif baru perbankan online dan layanan baru, dan dapat meningkatkan promosi di bidang pelayanan digital. Karyawan Bank Sumsel Babel diharapkan memberikan informasi dan edukasi kepada nasabah mengenai pelayanan digital pada saat pembukaan rekening dan pengenalan produk digital yang baru sehingga nasabah bisa beradaptasi dan bertranformasi ke pelayanan digital dalam proses upaya meningkatkan kepuasan nasabah Bank Sumsel Babel.

2. Manajemen Bank Sumsel Babel harus mempertahankan pelayanan konvensioanl dengan melakukan pelatihan bagi karyawannya secara berkala untuk peningkatan ilmu dan keahlian karyawan sehingga dapat meningkatkan kepuasan nasabah.

3. Kepada Manajemen Bank Sumsel Babel harus berinvestasi pada sumber daya manusia mereka untuk mengubahnya menjadi modal manusia, bahwa sumber daya manusia mampu untuk menjalankan tugas mereka sesuai dengan kondisi saat ini dan kecepatan teknologi di masa depan.

4. Penelitian ini memiliki keterbatasan hanya memilih Bank Sumsel Babel Cabang Prabumulih sehingga hasilnya adalah penggambaran untuk kantor Cabang saja. Diharapkan untuk penelitian selanjutnya dapat mengambil sampel dari beberapa Kantor Cabang Bank Sumsel Babel. Dan juga diharapkan dapat menambah variabel dan metode penelitian sebagai pembanding agar hasil yang didapat lebih maksimal.

\section{Referensi}

Mishra.U,S, Misra, B.B, Biswal, S.K, Mishra, B.B, 2010, "Employee Evaluation of Customer satisfaction : A Comparative Study Between Public and Private Banks in India”, International Research Journal of Finance \& Economics. ISSN 1450-2887. Issue, 59 (2010).

Deribe. B, Deribe. E, 2013, “Evaluation of Customer Satisfaction of Bank Service an Empirical Analysis”, Asia Journal of Business and Economics, Vol 3 No.3.

Nustini. Y, Fadhillah. N, 2020, "Factors that influence the use of e-Banking and the effect of consumptivism", Review of Integrative Business and Economics Research. Vol. 9. Supplementary Issue 1.

Maitlo GM , Kazi ZH, Khaskheley A and Faiz M.S, 2015, “Factors that Influence the Adoption of Online Banking Service in Hyderabad”. International Journal of Economics \& Management Sciences 4:216.

Maria Kristina Situmorang, 2021," Pengaruh Perilaku Konsumen Terhadap Penggunaan Uang Elektronik (Dompet Digital) Sebagai Alat Pembayaran Pada Masa Pandemi Covid - 19 di Kota Medan, MANEGGIO: Jurnal Ilmiah Magister Manajemen e-ISSN 2623-2634.

Polat, A, Yerilyaprak. M \& Kaya. R,2014, "Understanding Islamic Bank Selection of Customers : a field research from Turkish Participation Bank", International Journal of Financial Researc, Vol.5 No.4. 
Sharma. G, Malviya. S, "Exploring the Dimensions of mobile Banking Service Quality", http://ssrn.com/abstract $=2375548$ 